Distribution Category:

Nuclear Converter Reactor Fuel

Cycle Technology (UC-83)

ANL/RERTR/TM - 2

ARGONNE NATIONAL LABORATORY

9700 South Cass Avenue

Argonne, Illinois 60439

A STUDY OF $\mathrm{UO}_{2}$ WAFER FUEL

FOR VERY HIGH-POWER RESEARCH REACTORS

by

T. C. Hsieh, * V. Z. Jankus,

J. Rest, and M. C. Billone*t

Materials Science Division

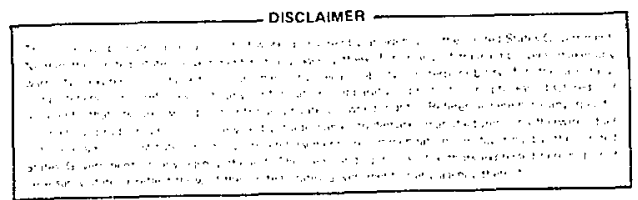

November 1980

* Present Address: EG\&G Idaho, Inc., Idaho Falls, Idaho 83401

**Present Address: Department of Mechanical and Nuclear Engineering,

Northwestern University, Evanston, Illinois 60201 
TABLE OF CONTENTS

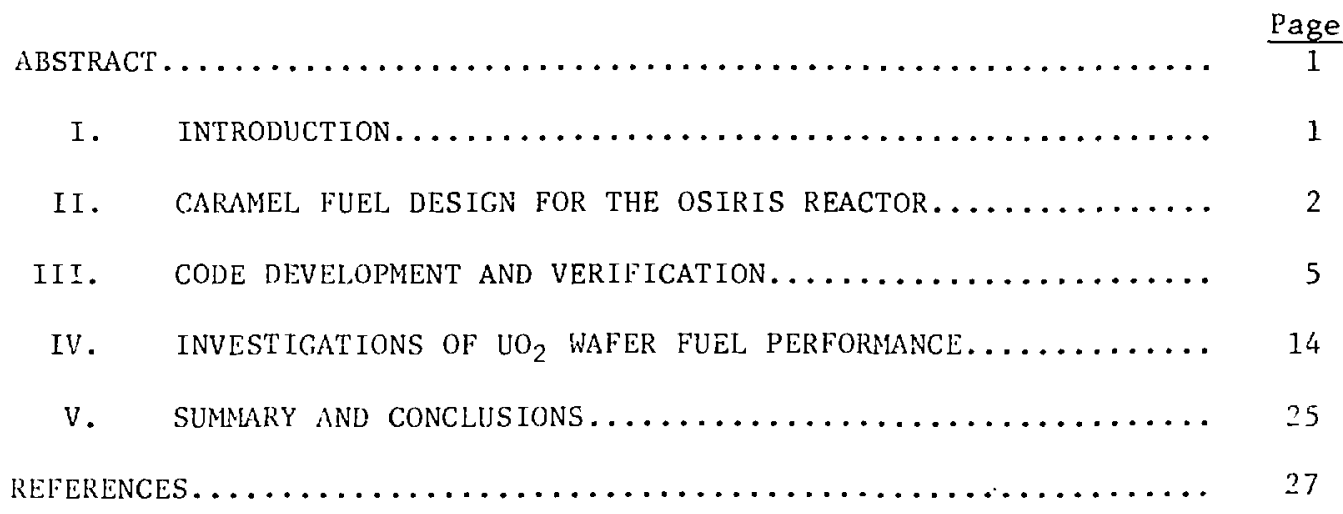




\section{Title}

No.

$\underline{\text { Page }}$

1. Schematic Representations of Cladding and Fuel Components for Compartmented Plate-type Oxide Fuel Elements. (a) Caramel fuel for the Osiris reactor; (b) fuel element for

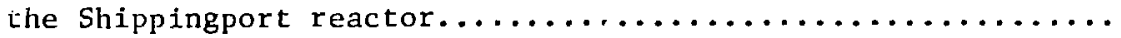

2. Schematic of Thin Plate-type Fuel and Cladding........... 5

3. Schematic of Hollow Cylindrical Fuel and Cladding.......... 6

4. Fuel Temperature Distributions in a Thin Plate and a Thin

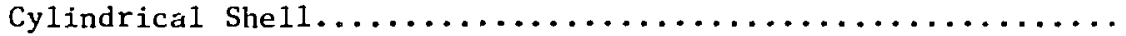

5. (a) A Thin Plate of Thickness 2c; (b) Cross Section of a Thin Cylindrical Shell with $r_{i}=a$ and $r_{0}=b \ldots \ldots \ldots \ldots \ldots$

6. Fuel Centerline Temperature vs Burnup for Four Caramel

Fuel Designs................................. 21

7. Fuel Failure Curves for Four Caramel Fuel Designs.......... 21

8. Fuel Centerline Temperature for the $1.45-\mathrm{mm}$ Wafer Design..... 21

9. Fuel Failure Curve for the 1.45-mim Wafer Design.......... 21

10. Fuel Failure Curve for a $1.50-\mathrm{mm}$ Wafer Under High Coolant

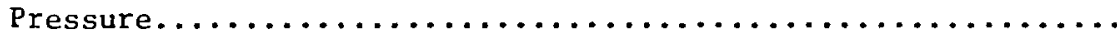

11. Fuel Failure Curve for a 1.50-r.n Wafer at a High Cladding

Surface Temperature...........................

12. Fuel Failure Curve for a 1.50-mm Wafer Under Power-cycling

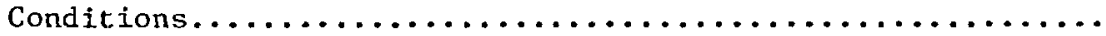




\section{LIST OF TABLES}

\section{Title}

No.

I. Design Parameters and Operating Conditions for Caramel

Fuel as Used in the osiris Reactor.................. 4

II. As-Built Data and Irradiation Conditions for Five Plate

Samples in NRX Reactor.......................... 15

III. LIFE-PLATE Predictions for Five Plate Fuel Samples.......... 16

IV. Fuel Plenum Volume, Fuel Density, and Initial Fuel Porosity for

Four Failed Plate Samples........................

V. Fuel Deformations Predicted by LIFE-PLATE for Five Plate

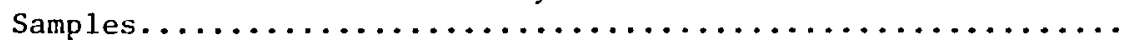

VI. Design Parameters for French Caramel Fuel Irradiated in

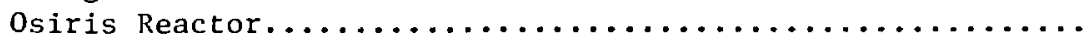

VII. Maximum Fuel Power Attainable at Two Different Goal

Burnups for Various Wafer Designs.................. 


\title{
A STUDY OF $\mathrm{UO}_{2}$ WAFER FUEL FOR VERY HIGH-POWER RESEARCH REACTORS
}

by

T. C. Hsieh, V. Z. Jankus, J. Rest and M. C. Billone

\begin{abstract}
The Reduced Enrichment Research and Test Reactor Program is aimed at reducing fuel enrichmert to $<20 \%$ in those research and test reactors presently using highly enriched uranium fuel. $\mathrm{UO}_{2}$ caramel fuel is one of the most promising new types of reduced-enrichment fuel for use in research reactors with very high power density. Parametric studies have been carried out to determine the maximum specific power attainable without significant fission-gas release for $\mathrm{UO}_{2}$ wafers ranging from 0.75 to $1.50 \mathrm{~mm}$ in thickness.
\end{abstract}

The results indicate that (1) all the fuel designs considered in this study are predicted not to fail under ful1power operation up to a burnup of $1.09 \times 10^{21} \mathrm{fis} / \mathrm{cm}^{3}$; (2) for all fuel designs, failure is predicted at approximately the same fuel centerline temperature for a given burnup; (3) the thinner the wafer, the wider the margin for fuel specific power between normal operation and increased-power operation leading to fuel failure; (4) increasing the coolant pressure in the reactor core could improve fuel performance by maintaining the fuel at a higher power level without failure for a given burnup; and (5) for a given power level, fuel fallure will occur earlier at a higher cladding surface temperature and/or under powercycling conditions.

\section{INTRODUCTION}

As part of the U. S. effort on proliferation resistance of fuels and fuel cycles, the Reduced Enrlchment Research and Test Reactor (RERTR) Program ${ }^{1}$ is aimed at reducing fuel enrichment to less than $20 \%$ in those research and test reactors presently using highly enriched uranium fuel. Generally, the enrichment reduction can be accomplished by increasing the total uranium loading of the fuel and/or by increasing the fuel volume fraction through element redesign. The candidate fuels for research and test reactors under this program ${ }^{2}$ include UA1 $-A 1$ dispersion fuel, $\mathrm{U}_{3} 0_{8}-\mathrm{Al}$ dispersion fuel, $\mathrm{U}_{3} \mathrm{Si}-\mathrm{Al}$ fuel, and $\mathrm{UO}_{2}$ fuef. The first two of these are current research reactor fuels with fuel loadings $01.2-1.7 \mathrm{~g} \mathrm{U} / \mathrm{cm}^{3}$, but with the potential for development of higher uranium loadings. $\mathrm{U}_{3} \mathrm{SI}-\mathrm{Al}$ and $\mathrm{UO}_{2}$ are new types of fuel which provide the enrichment-reduction potential for research reactors with very high power density (VHPD). In France, the CEA fuel development program aimed at reducing proliferation potential in research reactors has 
concentrated on $\mathrm{UO}_{2}$ caramel fuel, with $\mathrm{U}$-Mo alloys as a backup fuel. The French have successfully irradiated $\mathrm{UO}_{2}$ test wafers, arranged in Zircaloy separators and cladding ${ }^{3}$ in the 70-MW Osiris reactor, to a burnup of $7.26 \mathrm{x}$ $10^{20} \mathrm{fis} / \mathrm{cm}^{3}(30,000 \mathrm{MWd} / \mathrm{T})$.

In VHPD research reactors, the fuel centerline temperature must not approach a level at which a significant amount of fission gas is released from the fuel: The accumulation of released fission gas can push the cladding outward to form a fuel-cladding gas gap, thus causing a degradation of the heat transfer across the gap and subsequent higher fuel temperatures. Thase effects can eventually lead to fuel blistering and cladding breach. Owing to its poor thermal conductivity, $\mathrm{UO}_{2}$ wafer fuel must be fabricated in the form of thin $(<1.5-\mathrm{mm})$ plates to maintain a sufficiently low centerline temperature. The specific limitations on $\mathrm{UO}_{2}$ wafer thickness, which vary with research reactor type and irradiation conditions, in turn limit the specific power of the fuel. The purpose of the present report is to provide a description of the development of a production code for $\mathrm{UO}_{2}$ plate fuel and to report the results of parametric studies performed to establish the operating limits for $\mathrm{UO}_{2}$ wafer fuel in VHPD research reactors. Based on the available information on the French caramel fuel design and the operating conditions in the Osiris reactor, parametric studies have been carried out to determine the maximum fuel specific power possible before significant fission-gas release uccurs (causing the formation of a fuel-cladding gap) for $\mathrm{UO}_{2}$ wafer thicknesses of $1.50,1.45,1.25,1.00$ and $0.75 \mathrm{~mm}$. In the following section, French caramel fuel design for the Osiris reactor will be described. In Section III, a description of the development of a fuel modeling code for $\mathrm{LO}_{2}$ plate fuel and subsequent code verification will be given. The results of parametric studies are given and disclissed in Section IV, and conclusions are presented in Section $V$.

\section{CARAMEL FUEL DESIGN FOR THE OSIRIS REACTOR}

The French Osiris reactor is a pool-type reactor that used MTR-type 93\% enriched UAl fuel elements before conversion to caramel fuel in 1979 . The reactor first achieved criticality in 1966 and operated at the initial design power of 50 MW. The operating power was raised to $70 \mathrm{MW}$ in 1968 with the introduction of advanced UAl fuel elements. ${ }^{4}$ The UAl fuel elements were made of 24 flat plates with fuel meat dimensions of $0.508 \times 68.55 \times 600 \mathrm{~min}$ and a fuel loading of $16.3 \mathrm{~g} 235 \mathrm{U}$ per plate. The coolant flow rate and coolant pressure at the core inlet were $4,250 \mathrm{~m}^{3} / \mathrm{h}$ and $107.6 \mathrm{kPa}$ (15.6 psi), respectively.

The French caramel fuel design uses $v_{2}$ fuel (density of $10.25 \mathrm{~g} / \mathrm{cm}^{3}$ ) and Zircaloy cladding in a plate form. The ${ }^{235} \mathrm{U}$ enrichment is 1 ess than $10 \%$. The thickness of the $\mathrm{UO}_{2}$ fuel ranges from $4 \mathrm{~mm}$ for very low-power reactors and iritical experiments to $1.45 \mathrm{~mm}$ for VHPD research reactors. For the 70-MW Osiris reactor, the caramel fuel design utilizes $\mathrm{UO}_{2}$ wafers in a compartmentalized Zircaloy cladding arrangement (Fig. la). The wafer dimensions are $1.45 \times 17.1 \times 17.1 \mathrm{~mm}$ and the maximum fuel enrichment is $7 \% .5$ The caramel fuel design is similar to that employed in the second core of the Shippingport reactor (Fig. 1b), which used $\mathrm{UO}_{2}-\mathrm{ZrO}_{2}$ as fuel and $\mathrm{UO}_{2}$ in the blanket. 6 For complete replacement of UAl fuel by caramel fuel in the Osiris reactor, the coolant flow rate was increased by $30 \%$ (from 4,250 to $5,700 \mathrm{~m}^{3} / \mathrm{h}$ ) and the core volume was increased from 30 to 42 assemblies. Table I shows the design parameters of the caramel fuel elements and the operating conditions in the Osiris reactor. 


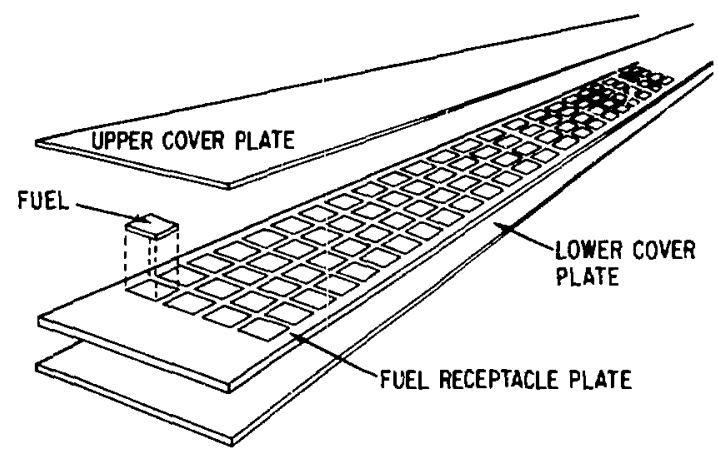

(a)

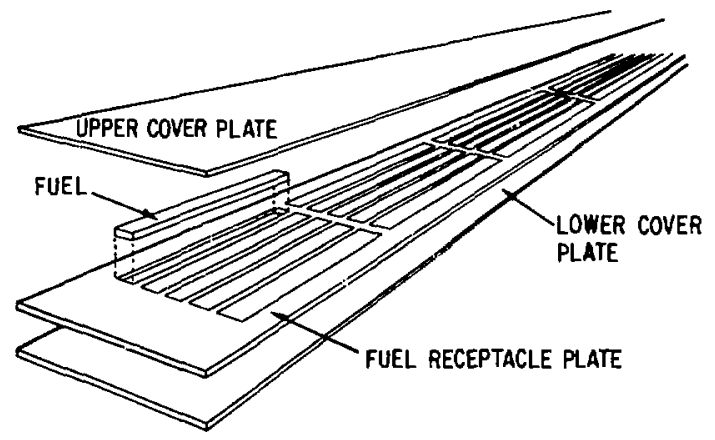

(b)

Fig. 1. Schematic Representations of Cladding and Fuel Components for Compartmented Plate-type Oxide Fuel Elements. (a) Caramel fuel for the Osiris reactor; (b) fuel element for the Shippingport reactor. 
Table I

Design Parameters and Operating Conditions for Caramel Fuel as Used in the Osiris Reactor

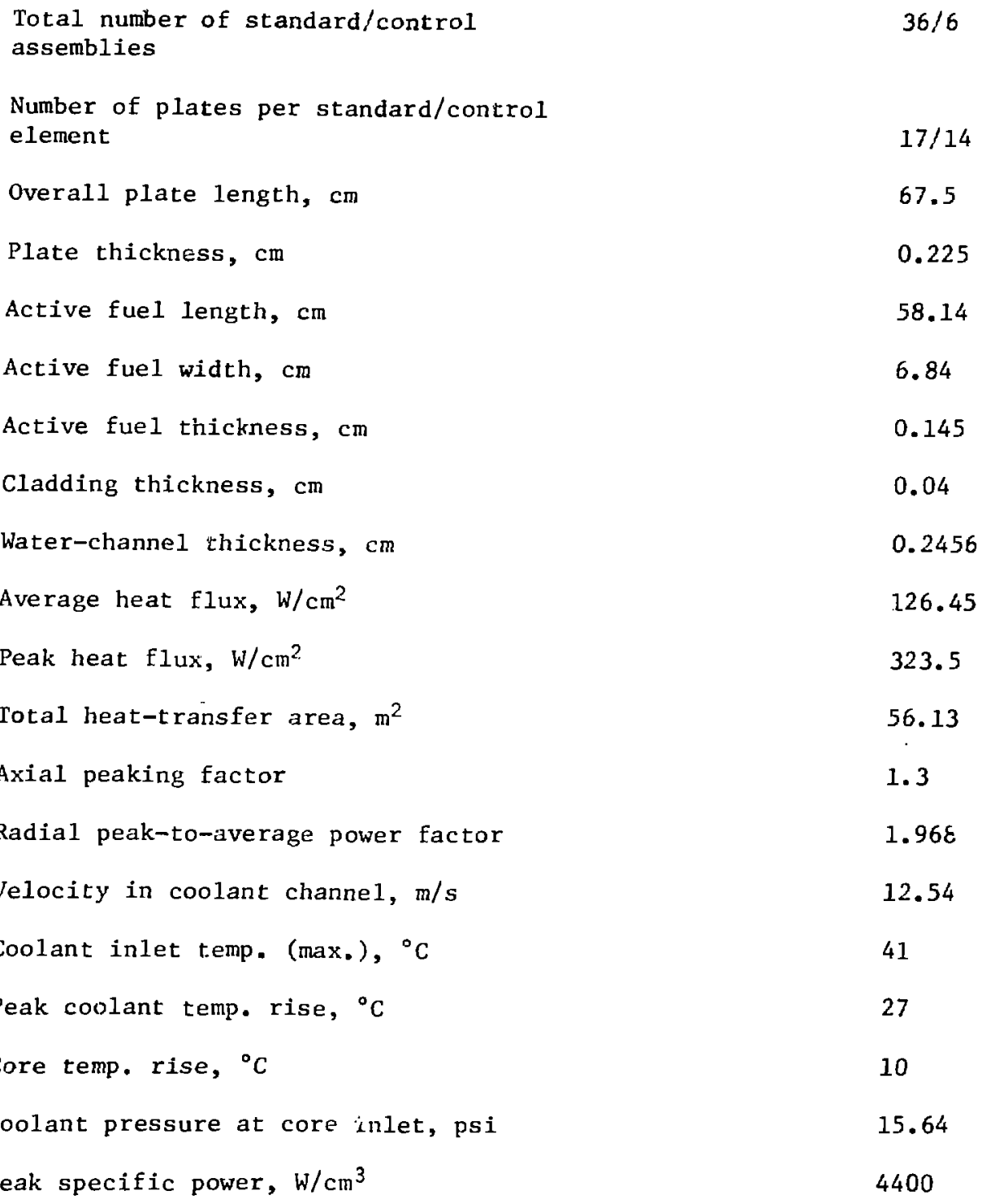




\section{CODE DEVELOPMENT AND VERIFICATION}

The thermal and mechanical behavior of the $\mathrm{UO}_{2}$ plate was analyzed by ineans of a computer code, LIFE-PLATE, generated from an existing production code, LIFE-LWR ${ }^{7}$, which was developed for cylindrical fuel under light water Reactor (LWR) operating conditions. The idea is to mathematically map the plate fuel into a thin, hollow cylindrical fuel with appropriate boundary conditions to achieve similarity in thermal and mechanical behavior between plate fuel and cylindrical fuel. In a plate fuel of dimensions $2 \mathrm{~S} \times \mathrm{W} \times \mathrm{L}$ (Fig. 2), the temperature distribution can be expressed as

$$
T_{p}(x)=T_{m}-\frac{q^{\prime \prime \prime}}{2 k_{f}} x^{2}
$$

where

$$
\begin{aligned}
& \mathrm{T}_{\mathrm{m}}=\text { fuel centerline temperature, } \\
& \mathrm{k}_{\mathrm{f}}=\text { fuel thermal conductivity, assumed constant, } \\
& \mathrm{q}^{\prime \prime \prime}=\text { fuel specific power, }
\end{aligned}
$$

and

$\mathrm{x} \quad$ = distance from fuel centerline.

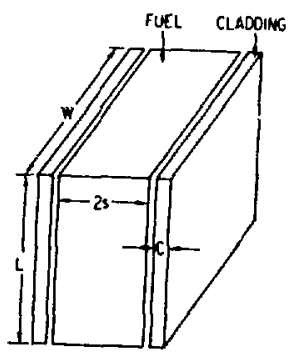

Fig. 2. So hematic of Thin Plate-type Fuel and Cladding.

With the same iuel material and irradiation conditions, the temperature distribution of a hollow, cylindrical fuel (Fig. 3) with inner radius, outer radius, and thickness $r_{i}, r_{0}$ and $s$, respectively, is (again assuming constant $k_{f}$ ) given by

$$
T_{r}(r)=T_{m}-\frac{q^{\prime \prime \prime} r_{i}^{2}}{4 k_{f}}\left[\left(-\frac{r}{r_{i}}\right)^{2}-2 \ln \frac{r}{r_{i}}-1\right] \text {. }
$$

Note that $T_{m}$ is the temperature at the inner cylinder surface, and no heat flow inward, i.e., into the center of the cylinder is allowed. 
Substituting $r=r_{i}+x$ into Eq. (2) results in

$$
\mathrm{T}_{\mathrm{r}}^{\prime}(\mathrm{x})=\mathrm{T}_{\mathrm{m}}-\frac{\mathrm{q}^{\prime \prime \prime} \mathrm{r}_{i}^{2}}{4 \mathrm{k}_{\mathrm{f}}}\left[\left(\frac{\mathrm{r}_{i}+\mathrm{x}}{\mathrm{r}_{i}}\right)^{2}-2 \ln \frac{\mathrm{r}_{i}+\mathrm{x}}{\mathrm{r}_{i}}-1\right] \text {. }
$$

The constant thermal conductivity, volumetric heat rating, outer surface temperature, and cylindrical thickness of the fuel, given by

$$
\begin{aligned}
& \mathrm{k}_{\mathrm{f}}=0.0252 \mathrm{~W} / \mathrm{cm}-{ }^{\circ} \mathrm{K}, \\
& \mathrm{q}^{\prime \prime \prime}=4552 \mathrm{~W} / \mathrm{cm}^{3}, \\
& T(S)=786.3^{\circ} \mathrm{C},
\end{aligned}
$$

and

$$
\mathrm{S} \quad=0.076 \mathrm{~cm} \text {, }
$$

are used to compare Eqs. (1) and (3).

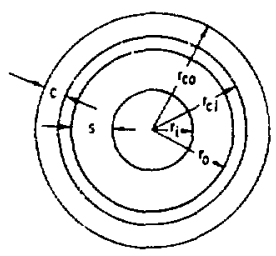

Fig. 3. Schematic of Hollow Cylindrical Fuel and cladding.

The fuel temperature distributions given by Eqs. (1) and (3) are shown in Fig. 4. In Fig. 4, the solid line represents the plate fuel temperature, the dotted line represents the cylindrical fuel temperature with $r_{i}=10 S$, and the dashed line represents the cylindrical fuel temperature with $r_{i}=50$. As shown in Fig. 4, with $r_{\text {; }}$ equal to 50 times the half-thickness of the plate fuel and with the same fuef outer surface temperature, the fuel temperature distribution in the cylindrical fuel is almost identical with that of the plate fuel; the maximum temperature difference, at the fuel centerline, is quite small $(<0.3 \%)$. For a plate cladding of dimensions $C \times W \times L$ (Fig. 2$)$ and a constant cladding thermal conductivity $k_{c}$, the temperature distribution in the cladding can be expressed as

$$
T_{p}(x)=T_{i}-\frac{q^{\prime \prime \prime} S x}{k_{c}},
$$

where

$$
\mathrm{T}_{i}=\text { cladding inner surface temperature, }
$$




$$
\begin{aligned}
& q^{\prime \prime}=\text { fuel specific power } \\
& S=\text { half thickness of the plate fuel, } \\
& \mathrm{x} \quad=\text { outward distance from the cladding inner surface, }
\end{aligned}
$$

and

$$
\mathrm{k}_{\mathrm{c}} \quad=\text { thermal conductivity of the cladding. }
$$

Similarly, the temperature distribution in a cyindrical cladding (Fig. 3 ) is

$$
T_{r}(r)=T_{i}-\frac{q^{\prime \prime \prime} \frac{\left(r_{0}^{2}-r_{i}^{2}\right)}{2} \ln \frac{r}{r_{c i}}}{k_{c}}
$$

or

$$
T_{r}^{\prime}(x)=T_{i}-\frac{q^{\prime \prime \prime} \frac{\left(r_{0}{ }^{2}-r_{i}{ }^{2}\right)}{2} \ln \frac{r_{c i}+x}{r_{c i}}}{k_{c}},
$$

where

$$
\begin{aligned}
& r_{0}=\text { fuel outer radius, } \\
& r_{i}=\text { fuel inner radius, } \\
& r_{c i}=\text { cladding inner radius, }
\end{aligned}
$$

and

$$
\mathrm{r}_{\mathrm{co}}=\text { cladding outer radius. }
$$

Given practical values of

$$
\begin{aligned}
& q^{\prime \prime \prime}=4552 \mathrm{~W} / \mathrm{cm}^{3}, \\
& k_{c}=0.164 \mathrm{~W} / \mathrm{cm}-{ }^{\circ} \mathrm{K}, \\
& r_{i .}=3.80 \mathrm{~cm}, \\
& r_{0}=3.876 \mathrm{~cm}, \\
& r_{c i}=3.886 \mathrm{~cm}, \\
& r_{c o}=3.946 \mathrm{~cm},
\end{aligned}
$$




$$
\begin{aligned}
& \mathrm{S}=\mathrm{r}_{\mathrm{o}}-\mathrm{r}_{i}=0.076 \mathrm{~cm}, \\
& r_{0}=(\text { cladding outer surface temperature })=130^{\circ} \mathrm{C},
\end{aligned}
$$

and

$$
\mathrm{C}=\mathbf{r}_{\mathrm{co}}-\mathbf{r}_{\mathrm{ci}}=0.06 \mathrm{~cm},
$$

one may calculate

$$
\begin{aligned}
& \mathrm{T}_{i}=130+\frac{4552 \cdot 0.076 \cdot 0.06}{0.1642}=256.4 \quad \text { (plate); } \\
& \mathrm{T}_{i}=130+\frac{4552 \cdot \frac{3.876^{2}-3.8^{2}}{2} \ln \frac{3.946}{3.886}}{0.1642}=253.9^{\circ} \mathrm{C} \quad \text { (cylinder). }
\end{aligned}
$$

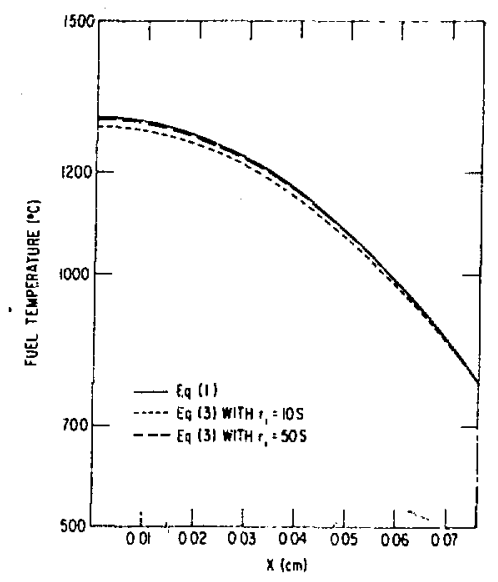

Fig. 4. Fue1. Temperature Distributions in'a Thin Plate and a Thin Cylindrical Shell.

Again, the cladding temperature distribution for the cylindrical ometry is almost identicai with that of the plate cladding; the maximum mperature difference (at the cladding inner surface) is very small ( $<1.0 \%$ ). erefore, the use of cylindrical geometry for representation of a flat plate valid in terms of the temperature distribution in both fuel and cladding, long as the inner radius of the cylindrical fuel is chosen to be 50 times -ger than the half-thickness of the plate fuel.

For the mechanical analysis, the thin-slab thermoelastic solution was pared with the thin-tube solution with regard to maximum tensile stress fuel and cladding outer surface) and maximum compressive stress (at fuel : cladding inner surface) to show the adequacy of employing a cylindrical metry for representation of a flat plate. 
For a thin slab of thickness 2c (Fig. 5a), the following assumptions are made:

(a) ingane stress, i.e., $\sigma_{z z}=0$.

(b) $\sigma_{\mathrm{xy}}=\sigma_{\mathrm{yz}}=\sigma_{\mathrm{zx}}$<smiles>[CH]1C=CC=C1</smiles>

(c) Temperature distribution in the slab is a function of $z$ only; i.e., $T=T(z)$.

(d) $\sigma_{x x}=f(z)$ and $\sigma_{y y}=f(z)$.

(e) The edges of the plate are perfectly restrained against expansion and rotation; i.e., $\varepsilon_{x x}=\varepsilon_{y y}=0$.

(f) Constant thermoelastic properties.

The thermoelastic solution is obtained from the stress-strain relationship as

$$
\sigma(z)=\frac{\bar{E} \bar{\alpha}}{1-\bar{\nu}}\left[-T(z)+\frac{1}{2 c} \int_{-c}^{c} T(z) d z\right] \text {. }
$$

For the thin sheli (Fig. $5 b$ ), the thermoelastic solution ${ }^{8}$ is given by

$\sigma_{\theta}(r)=\frac{\bar{E} \bar{\alpha}}{1-\bar{v}}\left[-T(r)+\frac{1+a^{2} / r^{2}}{1-a^{2} / b^{2}} \frac{1}{b^{2}} \int_{a}^{b} T(r)^{1} r d r+\frac{1}{r^{2}} \int_{a}^{r} T(r) r d r\right]$,

where
$a=$ the inner radius of the thin shell,
$b=$ the outer radius of the thin she11,

and

$\overline{\mathrm{E}}, \bar{\alpha}, \bar{\nu}=$ constants.

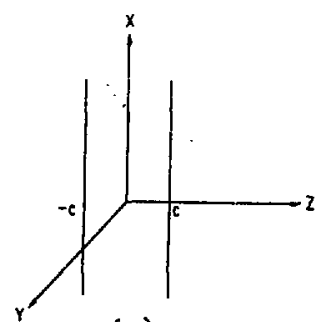

(a)

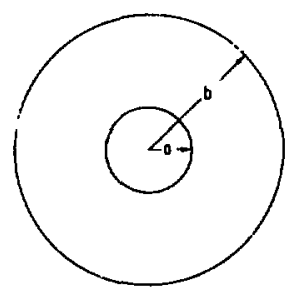

(b)

Fig. 5. (a) A Thin Plate of Thickness 2c; (b) Cross Section of a Thin Cylindrical Shell with $r_{i}=a$ and $r_{0}=b$. 
For fuel and cladding with $\frac{d T}{d z}$ and $\frac{d T}{d r} \leq 0$, the maximum tensile stress occurs at $z=c$ and $r=b$ for the siab and $\operatorname{shell}$ geometries, respectively. A linear temperature distribution in the cladding region is assumed for simplicity, i.e.,

$$
T(z)=T_{0}+\frac{\Delta T(c-z)}{2 c} \quad(\text { slab })
$$

and

$$
T(r)=T_{c}+\frac{\Delta T(b-r)}{b-a} \quad(\text { she11). }
$$

Substituting the above temperatures into Eqs. (7) and (8),

$$
\sigma(c)=1 / 2 \frac{\bar{E} \bar{\alpha} \Delta T}{1-\bar{v}}
$$

and

$$
\sigma_{\theta}(b)=\frac{\bar{E} \bar{\alpha} \Delta T}{1-\bar{v}} \frac{b+2 a}{3(b+a)}
$$

for maximum tensile stress, and

$$
\sigma(-c)=-1 / 2 \frac{\overline{\mathrm{E}} \bar{\alpha} \Delta \mathrm{T}}{1-\bar{\nu}}
$$

and

$$
\sigma_{\theta}(a)=-\frac{\bar{E} \bar{\alpha} \Delta T}{1-\bar{v}} \frac{a+2 b}{3(b+a)}
$$

for maximum compressive stress.

As the thickness of the wall ( $b$ - a) becomes small in comparison with the outer radius (b) of the cylinder, i.e., b/a $\rightarrow 1$, it can be shown that

$$
\sigma_{\theta}(\mathrm{b})=1 / 2 \frac{\bar{E} \bar{\alpha} \Delta \mathrm{T}}{1-\bar{v}}=\sigma(\mathrm{c})
$$

and

$$
\sigma_{\theta}(a)=-1 / 2 \frac{\bar{E} \bar{\alpha} \Delta T}{1-\bar{v}}=v(-c) \text {. }
$$

In order to evaluate the thermal stresses in the plate and thin shell for the case where $b / a \not-1$, consider $a=5.156 \mathrm{~cm}$ and $b=5.207 \mathrm{~cm}$. 
From Eqs. (12) and (14), it is seen that

$$
\sigma_{\theta}(b)=0.499 \frac{\ddot{E} \bar{\alpha} \Delta \mathrm{T}}{1-v}
$$

and

$$
\sigma_{\theta}(a)=-0.501 \frac{\bar{E} \bar{\alpha} \Delta \mathrm{T}}{1-\nu}
$$

Equations (17) and (18) are almost identical with Eqs. (15) and (16). Therefore, assuming a linear temperature distribution in the cladding for plate and cylindrical geometries, the distribution of thermal stresses over the thickness of the wall for a cylindrical shell is almost identical with that for a flat plate of thickness $2 c=b-a$.

For fuel, a quadratic temperature distribution is assumed:

$$
\mathrm{T}(\mathrm{z})=\mathrm{T}_{0}+\Delta \mathrm{T}\left[1-\left(\frac{z}{\mathrm{c}}\right)^{2}\right]
$$

and

$$
T(r)=T_{0}+\Delta T\left[1-\frac{(r-a)^{2}}{(b-a)^{2}}\right] .
$$

Substituting these temperatures into Eqs. (7) and (8), it is seen that

$$
\sigma(c)=\frac{2}{3} \frac{\overline{\mathrm{E}} \bar{\alpha}}{1-\nu} \Delta \mathrm{T}
$$

and

$$
\sigma_{\theta}(b)=\frac{\bar{E} \bar{\alpha} \Delta T}{1-\nu}\left[1-\frac{1}{6} \frac{(3 b+a)}{(b+a)}\right]
$$

For maximum tensile stress, and

$$
\sigma(-c)=-\frac{1}{3} \frac{\bar{E} \bar{\alpha}}{1-\nu} \Delta \mathrm{T}
$$

and

$$
\sigma_{\theta}(a)=\frac{\vec{E} \bar{\alpha} \Delta T}{1-v} \frac{1}{6}\left[\frac{(3 b+a)}{(b+a)}\right]
$$


for maximum compressive stress.

Again, with $b / a \rightarrow 1$, it is found that

$$
\sigma_{\theta}(b) \rightarrow \frac{2}{3} \frac{\bar{E} \bar{\alpha}}{1-\bar{v}}=\sigma(c)
$$

and

$$
\sigma_{\theta}(\mathrm{a}) \quad-\frac{1}{3} \frac{\bar{E} \bar{\alpha} \Delta \mathrm{T}}{1-\bar{v}}=\sigma(-\mathrm{c}) \text {. }
$$

In order to evaluate the thermal stresses in the plate and thin shell for the case where $b / a /-1$, consider

$$
\mathrm{a}=5.080 \mathrm{~cm}
$$

and

$$
\mathrm{b}=5.156 \mathrm{~cm} \text {. }
$$

These values lead to

$$
\sigma_{\theta}(b)=0.665 \frac{\bar{E} \bar{\alpha} \Delta T}{1-\bar{v}}
$$

and

$$
\sigma_{\theta}(a)=-0.335 \frac{\bar{E} \bar{\alpha} \Delta \mathrm{T}}{1-\bar{\nu}} .
$$

These calculations indicate that the maximum tensile and compressive stresses of ai cylindrical-shell fuel region are almost the same as those of a flatplate fuel region, assuming a quadratic temperature distribution in the fuel. Furthermore, the distribution of thermal stresses over the thickness of the wall for e cylindrical fuel is almost identical with the case of plate fuel of thickness $2 c=b-a$, since the temperature distribution over the thickness of the wall is identical in the two cases.

LIFE-PLATE is an integral fuel-modeling code that has been generated for $\mathrm{vo}_{2}$ plate fuel irradiated under normal operation conditions (i.e., startup, steady power, slow power changes and shutdown). The code is based on LIFE- LWR, which is an LWR fuel-rod performance code for $\mathrm{UO}_{2}$ fuel and $\mathrm{Zr}$ cladding. A number of modifications have been made in LIFE-LWR to generate LIFE-PLATE. These include the following:

(a) A code option has been added which allows the cladding outer surface temperature to be specified as an input to the code. The cladding surface temperature input to the code can be obtained from a simplified hand calculation or from a sophisticated thermal-hydraulics code. 
(b) A mechanistic gas release and sweIling code, FASTGRASS, 9 has been coupled to LIFE-PLATE to predict the fission-gas behavior in the fuel. The approach of coupling FASTGRASS to LIFE-PLATE is similar to that used in an experimental version of LIFE-LWR developed by Rest.10. After the operating conditions, such as fuel dimensions, local fuel temperatures and stresses, grain size, fuel densities, and linear power are calculated in LIFEPLATE, the FASTGRASS subroutine calculates the bubble radii for the various size classes of bubbles; the bubble diffusivities, mobilities, and coalescence probabilities; and the bubbie diffusion and migration rates. Then FASTGRASS solves for the bubble size distributions and calculates the amount of fission gas released and retained, as well as the fuel swelling strain due to retained fission gas. For plate wafer fuel, the amount of gas released from the fuel is crucial in deciding whether the fuel will fail or not. Therefore, a fundamental and reliable gas release and swelling code should be used.

(c) A boundary condition, which assumes that the pressure at the inner surface of the fuel (corresponding to the midplane of the plate fuel) is the same as the pressure of the coolant at the outer surface of the cladding, has been added to LIFE-PLATE. This assumption is based on the plane stress approximation to treat a flat plate. Practically, this boundary condition prevents cylindrical fuel and cladding, which are in intinate contact under steady-power operation before fuel failure, from creeping either inward or outward.

(d) The code is modified such that fission gas is not permitted to enter the central hole of the cylindrical fuel. However, fission gas released from the fuel is allowed to go into a hollow cylindrical plenum located at the top of the fuel, with radius as large as the inner radius of the cladding. Plenum size is specified according to the experimental observations of the fission gas release necessary to start the blistering and is treated in the code as a calibration parameter.

(e) During the opening of the fuel-cladding gap, caused by the accumulation of fission gas in the plenum, the plenum pressure is permitted to vary only within $\pm 3 \%$ of its value from the previous time step in order to eliminate numerical oscillations of the code (due to the small plenum in the $\mathrm{vO}_{2}$ wafer fuel).

LIFE-PLATE has been tested numerically using various coolant-pressure, fuelradius, fuel-cladding gap conductance, and fuel-length values to debug and streamline the code. LIFE-PLATE predictions have been compared with results of plate irradiation experiments which were conducted in the NRX reactor at Chalk River in 1960 by Westinghouse, II to ensure that the code is predicting reasonable fuel deformations and fission-gas releases. The irradiation program was part of the development of the $\mathrm{UO}_{2}$ plates for the blanket employed in the second core of the Shlppingport reactor. About $200 \mathrm{UO}_{2}$ wafer samples (including about 30 plates that had failed during irradiation) were irradiated. They covered a wide range of fuel densities ( $88-99 \%$ TD), fuel enrichments (3.8-63.7\%), fuel widths $(0.318-1.27 \mathrm{~cm})$, fuel wafer thicknesses $(0.76-4.06 \mathrm{~m})$, Irradiation temperatures $\left(254-324^{\circ} \mathrm{C}\right)$ at cladding $\mathrm{OD}$, and fuel burnups $(0.5-15.0$ at. $\%)$. 
Table II shows the as-fabricated data and irradiation conditions in the NRX reactor for five plate samples, M42-1C, M31-1C, 4H2-1A, 6H2-1A, and 2L2-1A. Each test element contained six or twelve fuel wafers (Fig. la) and was assembled, seal welded, evacuated, and then bonded at $843^{\circ} \mathrm{C}$ for 4 hours under a helium pressure of $69 \mathrm{MPa}(10,000 \mathrm{psi})$ without deliberate incorporation of a void volume. Table III shows LIFE-PLATE predictions of fission-gas release and iuel centerline temperature at the beginning of life for the five plate samples. Since neither the contact conductance of $\mathrm{UO}_{2}-\mathrm{Zircaloy}$ interfaces nor the contact pressures were known accurately, the above calculations were performed by assuming a constant gap conductance of $0.625 \mathrm{~W} / \mathrm{cm}^{2}{ }^{\circ} \mathrm{C}$. As shown in Table IV, fair agreement between measured and calculated fission-gas release was obtained. Fuel failures were observed in test. plates $M 42-2 C$, M31-1D, 2H1-2C and $1 \mathrm{H} 2-2 \mathrm{~A}$.

Based on the power history of the test samples, the plenum volume was adjusted in the code so that the opening of the fuel-cladding gap (taken as the onset of fuel blistering here) predicted by LIFE-PLATE would be in agreement with the experimental observations. Table IV shows plenum volumes, fuel densities, and initial fuel porosities for test samples M42-2C, M31-1D, $2 \mathrm{H} 1-2 \mathrm{C}$ and $1 \mathrm{H} 2-2 \mathrm{~A}$. The plenum volume is very close to the initial fuel porosity in each failed plate. With plenum volumes equal to the initial fuel porosities, LIFE-PLATE predicted no fuel failures for test runs $4 \mathrm{H} 2$ and $2 \mathrm{~L} 2$, in agreement with experimental data. Therefore, the plenum volume was set equal to the initial fuel porosity in the code.

The fuel deformations predicted by LIFE-PLATE have also heen qualitatively compared with the experimental data for plate samples $M 42-1 \mathrm{C}, \mathrm{M} 31-1 \mathrm{C}$, $4 \mathrm{H} 2-1 \mathrm{~A}, 6 \mathrm{H} 2-1 \mathrm{~A}$, and 2L2-1A ('leble V). For eact test element, the measurements were made at several positions and only the average value was reported, while LIFE-PLATE predictions are for the maximum fuel deformation at the center of the plate. As shown in Table $\mathrm{V}$, the predictions made by LIFE-PLATE agree fairly well with the experimental data.

\section{INVESTIGATIONS OF $\mathrm{UO}_{2}$ WAFER FUEL PERFORMANCE}

Parametric studies with $\mathrm{UO}_{2}$ wafer thickness ranging from 0.75 to $1.50 \mathrm{~mm}$ were conducted for caramel fuel irradiated in the Osiris reactor to determine the $n$ iximum specific power at which significant fission-gas release and gap opening would occur. The fuel design is taken from Ref. 3 and the design parameters are listed in Table VI. Owing to limited information on French caramel fuel design and operating conditions in the Osiris reactor, most data in Table VI are our best guesses. Table VI gives the possible design parameters for $0.75,1.00,1.25$ and 1.50 -mm-thick fuel wafers. In these designs, the cladding thickness, reactor core size and power, and coolant mass flow rate are kept the same. The fuel enrichment has been increased for thin wafer designs to compensate for the decrease in fuel volume fraction. The parametric studies are based on the data listed in Table VI, which differ from those of Table I; however, at the end of this section, it will be shown that the domain of these parametric studies actually included the design case given in Table $I$. The studies were based on the following assumptions: 
Table II

As-built Data and Irradiation Conditions for Five Plate Samples in NRX Reactor Fuel Sample

\begin{tabular}{|c|c|c|c|c|c|}
\hline & M42-1C & M31-1C & $4 \mathrm{H} 2-1 \mathrm{~A}$ & $6 \mathrm{H} 2-1 \mathrm{~A}$ & $2 \mathrm{~L} 2-1 \mathrm{~A}$ \\
\hline Width, ${ }^{a}$ & 0.635 & 0.635 & 0.635 & 0.318 & 0.635 \\
\hline${ }^{235}$ U Enrichment, wt\% & 52.1 & 52.1 & 52.0 & 63.7 & 55.4 \\
\hline Fuel Density, \% TD & 88 & 97 & 97 & 97 & 87 \\
\hline $\begin{array}{l}\text { Cladding Thickness, } \\
\mathrm{cm}\end{array}$ & 0.051 & 0.051 & 0.051 & 0.051 & 0.051 \\
\hline $\begin{array}{c}\text { Coolant Pressure, } \\
\text { psi }\end{array}$ & 2000 & 2000 & 2000 & 2000 & 2000 \\
\hline $\begin{array}{l}\text { Average Heat } \mathrm{Flux}, \\
\mathrm{W} / \mathrm{cm}^{2}\end{array}$ & 167.2 & 179.8 & 201.9 & 186.1 & 173.5 \\
\hline Burnup, at. $\%$ & 14.89 & 7.88 & 7.45 & 13.58 & 7.88 \\
\hline
\end{tabular}

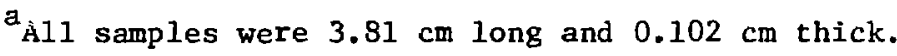


Table III

LIFE-PLATE Predictions for Five Plate Fuel Samples

\begin{tabular}{|c|c|c|c|c|}
\hline \multirow[b]{2}{*}{ Fue 1 Sample } & \multirow[b]{2}{*}{ Burnup, at.\% } & \multicolumn{2}{|c|}{$\begin{array}{r}\text { Fission Gas } \\
\text { Released, \% Th } \\
\end{array}$} & \multirow{2}{*}{$\begin{array}{l}\text { Fuel Centerline } \\
\text { Temp. BOL, }{ }^{\circ} \mathbf{F}\end{array}$} \\
\hline & & Measured & Calculated & \\
\hline M42-1C & 14.89 & 14.1 & 8.38 & 1708 \\
\hline M31-1C & 7.88 & 3.7 & 3.75 & 1657 \\
\hline $\mathrm{UH} 2-1 \mathrm{~A}$ & 7.44 & 2.8 & 4.50 & 1695 \\
\hline $6 G 2-1 A$ & 13.58 & 7.8 & $6: 84$ & 1680 \\
\hline $2 \mathrm{~L} 2-1 \mathrm{~A}$ & 7.88 & 4.1 & 6.32 & 1828 \\
\hline
\end{tabular}


Table IV

Fuel Plenum Volume, Fuel Density, and Initial Fuel Porosity for Four Failed Plate Samples

\begin{tabular}{lccc}
\hline Test Plate & $\begin{array}{c}\text { Plenum Volume, } \\
\text { percent of fuel volume }\end{array}$ & $\begin{array}{r}\text { Fuel Density, } \\
\% \text { TD }\end{array}$ & $\begin{array}{c}\text { Initial Fuel } \\
\text { Porosity, } \\
\%\end{array}$ \\
M42-2C & 12.3 & 88 & 12 \\
1H2-2A & 1.7 & 97 & 3 \\
$2 \mathrm{H} 1-2 \mathrm{C}$ & 2.7 & 97 & 3 \\
\hline
\end{tabular}

Table V

Fue1 Deformations Predicted by LIFE-PLATE for Five Plate Samples

\begin{tabular}{lccc}
\hline Fue1 Sample & Burnup, at.\% & \multicolumn{2}{c}{$\Delta t$ (nils) } \\
\cline { 2 - 2 } & 15.81 & 2.1 & \multicolumn{1}{c}{ Measured (average) } \\
M31-1C & 7.59 & 2.1 & 3.08 \\
4H2-1A & 7.17 & 1.5 & 2.1 \\
6H2-1A & 13.08 & 4.1 & 3.94 \\
$2 \mathrm{~L} 2-1 \mathrm{~A}$ & 8.47 & 2.0 & 3.0 \\
\hline
\end{tabular}


Table VI Design Parameters ${ }^{a}$ for French Caramel Fuel Irradiated in
Ostris Reactor

\begin{tabular}{|c|c|c|c|c|}
\hline & \multicolumn{4}{|c|}{ Wafer Thickness, mm } \\
\hline & 0.75 & 1.00 & 1.25 & 1.50 \\
\hline $\begin{array}{l}\text { No. of fuel plates per } \\
\text { fuel element }\end{array}$ & 20 & 18 & 17 & 16 \\
\hline Plate thickness, mm & 1.77 & 2.02 & 2.27 & 2.52 \\
\hline $\begin{array}{l}\text { Active fuel thickness, } \\
\text { mm }\end{array}$ & 0.75 & 1.00 & 1.25 & 1.50 \\
\hline $\begin{array}{l}\text { Water channel thick- } \\
\text { ness, mm }\end{array}$ & 2.35 & 2.56 & 2.58 & 2.63 \\
\hline $\begin{array}{l}\text { Average heat flux, } \\
\mathrm{W} / \mathrm{cm}^{2}\end{array}$ & 115.74 & 128.60 & 136.17 & 144.68 \\
\hline $\begin{array}{l}\text { Total heat transfer } \\
\text { area, } \mathrm{m}^{2}\end{array}$ & 60.48 & 54.43 & 51.41 & 48.38 \\
\hline $\begin{array}{l}\text { Veloctty in coolant } \\
\text { channel, } \mathrm{m} / \mathrm{s}\end{array}$ & 10.31 & 10.48 & 11.1 & 11.47 \\
\hline $\begin{array}{l}\text { Peak specific power, } \\
\mathrm{W} / \mathrm{cm}^{3} \text { oxide }\end{array}$ & 7283 & 6070 & 5060 & 4552 \\
\hline Fuel enrichment, $\%$ & 11.2 & 9.4 & 8 & 7 \\
\hline \multicolumn{5}{|c|}{$a_{\text {The following design parameters are the same for all four wafer designs: }}$} \\
\hline \multicolumn{2}{|c|}{ Total no. of fuel assemblies - 45} & \multicolumn{3}{|c|}{ Core temp. rise, ${ }^{\circ} \mathrm{C}-25.1$} \\
\hline No. of wafers per plate & -84 & \multicolumn{3}{|c|}{$\begin{array}{l}\text { Coolant pressure at }-15.64 \\
\text { core inlet, psi }\end{array}$} \\
\hline $\begin{array}{l}\text { Active fuel length, cm } \\
\text { Clad thlckness, }\end{array}$ & $\begin{array}{l}-56 \\
-\quad 0.51\end{array}$ & \multicolumn{2}{|c|}{$\begin{array}{l}\text { Fast neutron flux, } \\
\text { avg/max }\end{array}$} & $\begin{array}{l}-\quad 1.94 / \\
4.16 \times 10^{14}\end{array}$ \\
\hline $\begin{array}{l}\text { Radial peak-to-average } \\
\text { power factor }\end{array}$ & -2.36 & \multicolumn{2}{|c|}{$\begin{array}{l}\text { Thermal neutron } \\
\text { flux, avg/max }\end{array}$} & $0.85 / 2 \times 10^{14}$ \\
\hline
\end{tabular}


(a) The fabrication processes for French caramel fuel are the same as those for elements of the $x-1-p$ and $x-3-m$ tests, which included test samples of $M 42-1 C$, M31-1C, 4H2-1A, 6H2-1A, and 2L2-1A: 1.e., fue 1 platelets that were sintered at $1750^{\circ} \mathrm{C}$, onated with 0.356-1.02 $\mu \mathrm{m}$ of pyrolytic carbon by cracking methane at $1030^{\circ} \mathrm{C}$ and isostatically pressure bonded without deliberate incorporation of any void volume.

(b) Before fuel-cladding gap opening, the gap conductance has a constant value of $0.625 \mathrm{~W} / \mathrm{cm}^{2} \mathrm{C}$, and the plenum volume is $6.5 \%$ of total fuel volume.

(c) A constant water film coefficient of $4.54 \mathrm{~W} / \mathrm{cm}^{2}{ }^{\circ} \mathrm{C}$ can be used in the cladding OD temperature calculations.

(d) There is no heat transfer through fuel-cladding interfaces in the thickness-length plane (..e., ribs).

For each fuel wafer design, the performance of the hottest wafer was analyzed by using LIFE-PLATE. Figure 6 shows the centerline temperatures of the peak power wafers irradiated in the Osiris reactor vs fuel burnups of up to $1.09 \times 10^{21} \mathrm{fis} / \mathrm{cm}^{3}(45,000 \mathrm{MWd} / \mathrm{T})$ and for wafer thicknesses of 1.50 , $1.25,1.00$, and $0.75 \mathrm{~mm}$. As shown in $\mathrm{Fig} .6$, the thinner the wafer, the lower the calculated fuel centerline temperature. By varying the specific power of the $\mathrm{UO}_{2}$ fuel in each wafer design (assuming cladding oD temperature and irradiation conditions remain the same), LIFE-PLATE predicts the time at which the fuel-cladding gap starts to form as a result of the internal pressure arising from the accumulation of fission gas released from the fuel. In LIFE-PLATE, when plenum pressure exceeds fuel-cladding interfacial pressure by one percent, a gap between fuel and cladding is allowed to form. The opening of the gap will cause degradation in the fuel-cladding heat transfer and will lead to high fuel temperature. These processes will lead to fuel blistering and cladding failure. Therefore, for a conservative approach, the opening of the gap can be regarded as the onset of fuel blistering and fuel failur.. The curve of fuel specific power vs time of fuel failure (as described above) is defined here as the fuel fallure curve. Figure 7 shows the fuel failure curves for $1.50,1.25,1.00$, and $0.75-\mathrm{mm}$-thick fuel designs.

In order to clarify the meaning of the fuel fallure curves in Fig. 7, we will consider the following example for a 1.50-mm-thick wafer design. Under full power, the peak specific power (which is used here to mean fuel power per unit volume of oxide fuel) of the fuel wafer is 4552 $W / \mathrm{cm}^{3}$ and LIFE-PLATE predicts that there 18 no gap between fuel and cladding up to a burnup of $1.09 \times 10^{21} \mathrm{fis} / \mathrm{cm}^{3}(45,000 \mathrm{MWd} / \mathrm{T})$. However, if the fuel specific power were raised to $5462 \mathrm{~W} / \mathrm{cm}^{3}$, LIFE-PLATE would predict fuel failure at a burnup of $6.29 \times 10^{20} \mathrm{fis} / \mathrm{cm}^{3}(26,000 \mathrm{MHd} / \mathrm{T})$ and thus generate a point on the fuel fallure curve (Fig. 7 ).

Figures $B$ and 9 show the fuel centerline temperature under fullpower conditions and the fuel fallure curve, respectively, for the standard 


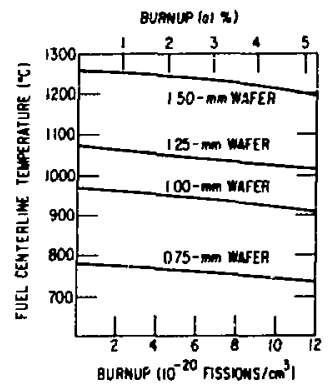

Fig. 6. Fuel Centerline Temperature vs Burnup for Four Caramel Fuel Designs.

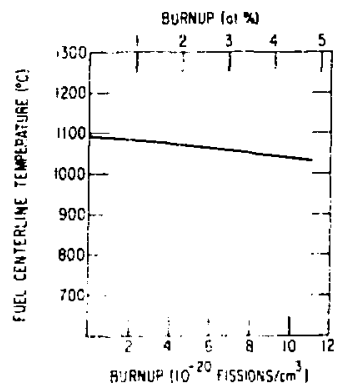

Fig. 8. Fuel Centerline Temperature for the 1.45-mm Wafer Design.

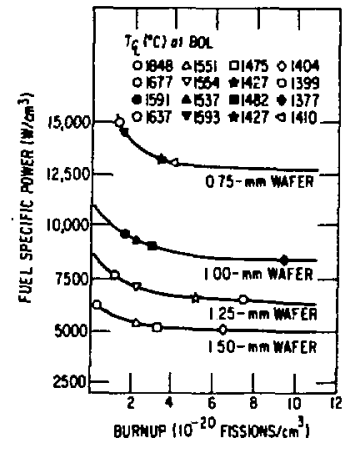

Fig. 7. Fuel Failure Curves for Four Caramel Fuel Designs.

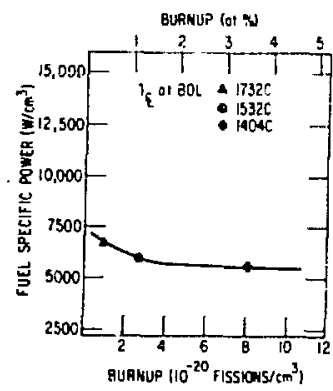

Fig. 9. Fuel Failure Curve for the 1.45-mm Wafer Design.

(1.45-mm-thick) caramel wafer design according to the data listed in Table $I$. Comparing Fig. 8 with Fig. 5 , one sees that the fuel centerline temperature of 1.50-mm-thick fuel (data taken from Ref. 3) is about $167^{\circ} \mathrm{C}$ bigher than that of 1.45-mm-thick fuel (data taken from Ref. 5). This is due mainly to the lower average heat flux and thinner cladding of the fuel in the $1.45-\mathrm{mm}$ fuel design. The following observations can be made: (a) All of the fuel wafer designs considered are predicted not to fail under full-power operations up to a burnup of $1.09 \times 10^{21} \mathrm{fis} / \mathrm{cm}^{3}(45,000 \mathrm{MWd} / \mathrm{t})$. (b) For each fuel design and a given initial fuel temperature, the fuel is predicted to fail at approximately the same burnup (Fig. 7). (c) The thinner the wafer, the larger the margin that exists for fuel specific power between normal operation and increased-power operation leading to fuel failure. (d) For the same goal burnup, the thinnest wafer design has the shortest residence time in the core. This conclusion is based on the assumption that the cladding thicknesses and reactor core sizes are the same in all four wafer designs. The increases in fuel enrichment, which are required in thin wafer designs to compensate for 
the decrease in fuel volume fraction in the core and to reach criticality, cause the decrease of fuel residence time for a given goal burnup. If the fabrication technology allows the cladding thicknesses to be varied in proportion to wafer thicknesses, e.g., a cladding thickness of 0.51 mim for a 1.50-mm wafer design and a cladding thickness of $0.26 \mathrm{~mm}$ for a $0.75-\mathrm{mm}$ wafer design, then

$$
q^{\prime \prime}(0.75-m m \text { wafer })=\frac{1}{2} q^{\prime \prime}(1.50-\operatorname{mm} \text { wấer })
$$

and

$$
\begin{aligned}
q^{\prime \prime \prime}(0.75-\mathrm{mm} \text { wafer }) & =\frac{2 q^{\prime \prime}(0.75-\mathrm{mm} \text { wafer })}{0.75}=\frac{2 q^{\prime \prime}(1.50-\mathrm{mm} \text { wafer })}{1.50} \\
& =q^{\prime \prime \prime}(1.50-\mathrm{mm} \text { waf er })
\end{aligned}
$$

where

$q^{\prime \prime}=$ heat flow rate of fuf:l per unit area

and

$q^{\prime \prime \prime}=$ fuel specific power.

Thus, the fuel specific powers and fuel enrichments are the same in all four wafer designs (neglecting flux depression), and fuel residence time would be the same to a given burnud. Table VII shows the maximum specific power each wafer design can reach before fuel failuie for the goal burnups of $7.26 \mathrm{x}$ $10^{20}$ and $1.09 \times 10^{21} \mathrm{fis} / \mathrm{cm}^{3}(30,000$ and $45,000 \mathrm{MWd} / \mathrm{T})$. The fuel centerline temperature at each fuel power level at the beginning of life is also included. The values of peak specific power listed in Table VII can be interpreted as follows: Under steady reactor power conditions similar to that of the Osiris reactor, if the peak fuel specific power was increased to 4,940, $5,350,6,440,8,500$, and $12,600 \mathrm{~W} / \mathrm{cm}^{3}$ for the $1.50,1.45,1.25,1.00$ and $0.75-$ mn wafer designs, respectively (through increases in fuei enrichment), the wafer designs could be used in the research reactors with powers of 76,85 , 89,98 , and $123 \mathrm{MW}$, respectively, to a fuel burnup of $1.09 \times 10^{21} \mathrm{fis} / \mathrm{cm}^{3}$ $(45,000 \mathrm{MHd} / \mathrm{T})$ without fuel fallure. Under the above reactor powers, the fuel centerline temperatures at the beginning of life for all five wafer designs are about the same $\left(\sim 1400^{\circ} \mathrm{C}\right)$ The fuel residence time for peakpower wafers is $93.4,86.2,71.6,54.3$, and 36.6 days for the $1.50,1.45$, $1.25,1.00$, and 0.75 mm wafer designs, respectively.

Fuel failure could conceivably be affected by factors such as coolant pressure, cladding temperature, and power cycling. Figure 10 shows the fuel failure curve for the $1.50-\mathrm{mm}$ wafer design under similar operating conditions in the Osiris reactor with a coolant pressure of $6.9 \mathrm{MPa}$ (i.e., a much larger coolant pressure than used in the previous calculations). The maximum specific power a fuel wafer can sustain is 5,460 and $5,280 \mathrm{w} / \mathrm{cm}^{3}$ for burnups of $7.26 \times 10^{20}$ and $1.09 \times 10^{2 \mathrm{l}} \mathrm{fis} / \mathrm{cm}^{3}(30,000 \& 45,000 \mathrm{MWd} / \mathrm{T})$, respectively, about 10\% higher than that listed in Table VII. The higher coolant pressure exerted on the cladding surface will make the formation of a fuel-cladding gas gap more difficult, i.e., release of more fission gas from the fuel is required to generate a pressure great enough to overcome the coolant pressure and forn the 
Table VII

Maximum Fuel Power Attainable at Two Different

Goal Burnups for Varfous Wafer Designs

\begin{tabular}{|c|c|c|c|}
\hline afer Thickness, mm & $\begin{array}{c}\text { Goal Burnup, } \\
\mathrm{f} 1 \mathrm{~s} / \mathrm{cm}^{3} \\
\end{array}$ & $\begin{array}{l}\text { Peak Specific Power, } \\
W / \mathrm{cm}^{3} \text { Oxide }\end{array}$ & $\begin{array}{l}\text { Fuel Centerline } \\
\text { Temp. BOL, }{ }^{\circ} \mathrm{F}\end{array}$ \\
\hline 0.75 & $\begin{array}{l}7.26 \times 10^{20} \\
1.09 \times 10^{21}\end{array}$ & $\begin{array}{l}12,700 \\
12,600\end{array}$ & $\begin{array}{l}2,560 \\
2,540\end{array}$ \\
\hline 1.00 & $\begin{array}{l}7.26 \times 10^{20} \\
1.09 \times 10^{21}\end{array}$ & $\begin{array}{l}8,620 \\
8,500\end{array}$ & $\begin{array}{l}2,540 \\
2,500\end{array}$ \\
\hline 1.25 & $\begin{array}{l}7.26 \times 10^{20} \\
1.09 \times 10^{21}\end{array}$ & $\begin{array}{l}6,470 \\
6,470\end{array}$ & $\begin{array}{l}2,560 \\
2,500\end{array}$ \\
\hline 1.45 & $\begin{array}{l}7.26 \times 10^{20} \\
1.09 \times 10^{21}\end{array}$ & $\begin{array}{l}5,540 \\
5,350\end{array}$ & $\begin{array}{l}2,570 \\
2,480\end{array}$ \\
\hline 1.50 & $\begin{array}{l}7.26 \times 10^{20} \\
1.09 \times 10^{21}\end{array}$ & $\begin{array}{l}4,980 \\
4,940\end{array}$ & $\begin{array}{l}2,550 \\
2,520\end{array}$ \\
\hline
\end{tabular}




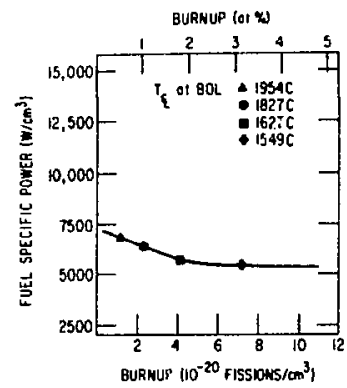

Fig. 10. Fuel Failure Curve for a 1.50-mm Wafer Under High Coolant Pressure.

gas gap. Therefore, for a given fuel specific power, the effect of higher coolant pressure is to prolong the time to fuel failure and, for a given fuel burnup, the effect of higher coolant pressure is that the fuel can operate at a higher power level.

If the fuel wafer were irradiated with a higher cladding temperature, one would expect a higher fuel centerline temperature [from Eq. (1), the fuel surface temperature is higher] and release of a larger amount of fission gas from the fuel for the same power level. This effect is shown in Fig. 11, which gives results for a $1.50-\mathrm{mm}$ wafer irradiated with a cladding temperature of $260^{\circ} \mathrm{C}$. The fuel is predicted to fall at a burnup of $\sim 1.7 \mathrm{\times} 10^{20} \mathrm{fis} / \mathrm{cm}^{3}$ at a fuel power of $5,240 \mathrm{~W} / \mathrm{cm}^{3}$.

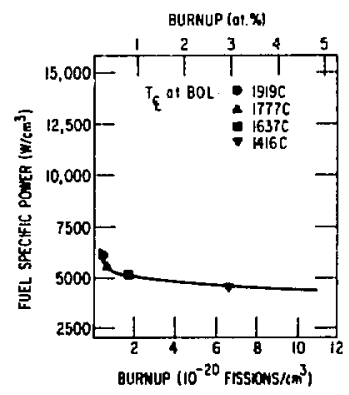

Fig. 11. Fuel Fallure Curve for a 1.50-mm Wafer at a High Cladding Surface Temperature.

Figure 12 shows the fuel fallure curve for a 1.50-mm wafer trradiated in the Osiris reactor under power-cycling conditions. The reactor power is assumed to start up and shut down every 200 hours. For a very high fuel specific power (say, $5,500 \mathrm{~W} / \mathrm{cm}^{3}$ ), the power-cycling effect is not promfnent because the fuel falls before the end of one or two power cycles. Therefore, 


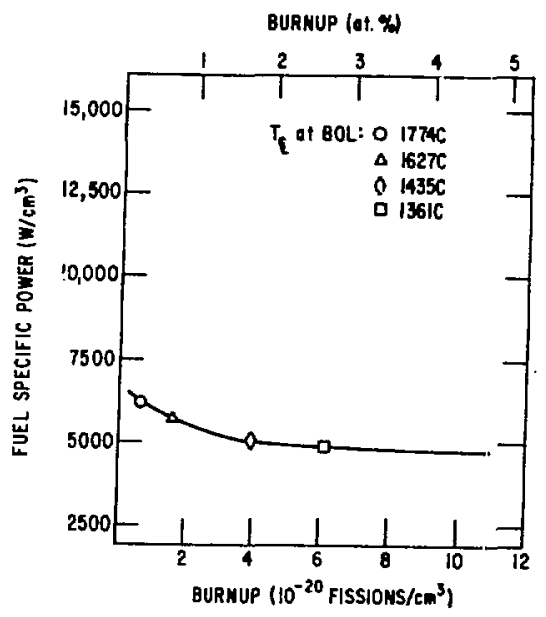

Fig. 12. Fuel Failurs Curve for a 1.50-mm Wafer Unider Power-cycling Conditions.

there is no significant difference between Figs. 7 and 12 with respect: to the high-power regions of the $1.50-\mathrm{mm}$ fuel failure curves. At a fuel spectfic power of $5,010 \mathrm{~W} / \mathrm{cm}^{3}$, power-cycling conditions and steady-power operation will result in fuel failure at burnups o: $4.84 \times 10^{20}$ and $6.05 \times$ $10^{20} \mathrm{fis} / \mathrm{cm}^{3}(20,000$ and $25,000 \mathrm{MWd} / \mathrm{T})$, respectively. Here, the earlier fuel fallure for the power-cycling case is due to the larger fuel deformations and greater amount of gas release from the fuel.

\section{SUMMARY AND CONCLUSIONS}

The potential for conversion of any reactor to reduced-enrichment fuel generally depends on the reactor type, the current uranium density in the fuel, and the power density, and must be assessed on an individual basis. The evauluation of the fuel design depends on the fuel-cycle cost and fuel performance. An economical fuel-cycle cost requires thick plates separated by wide water channels. High fuel performance, on the other hand, is achieved with thin plates and narrow water gaps. The proposed compromise will depend on the characteristics of each reactor. LIFE-PLATE analysis of the French caramel fuel, which is designed specifically for the Osiris reactor, indicated that the goal burnup of $1.09 \times 10^{21} \mathrm{fis} / \mathrm{cm}^{3}(45,000 \mathrm{MWd} / \mathrm{T})$ will be reached without fuel failure by the peak-power wafer under full-power conditions for $1.50,1.45,1.25,1.00$, and $0.75-\mathrm{mm}$ wafer designs. At the Indicated goal burnup, these designs would allow a maximum spectfic power of $4940,5350,6440,8550$, and $12,600 \mathrm{~W} / \mathrm{cm}^{3}$, respectively. The thinner the wafer, the larger the margin that exists for fuel specific power between normal operation and increased-power operation leading to fuel failure. Thin wafers provide the potential for fuel conversion for even high-powr ( $>70 \mathrm{MW}$ ) research reactors. Very high fuel performance can be achieved with a fuel design that uses thin wafers as well as thin cladding. Increasing the coolant pressure in the reactor core could improve the fuel performance, by mairtaining the fuel at a higher power level without failure for a given burnup. Fuel fallure will occur earlier for a given power level at a 
higher cladding surface temperature and/or under power-cycling conditions.

The new fuel types considered for conversion of very high-power research rea:tors include $\mathrm{U}_{3} \mathrm{Si}, \mathrm{U}-\mathrm{Mo}$ alloys, and $\mathrm{UO}_{2}$ fuel, which are all in the form of flat plates. With modifications in descriptions of fission-gas release and swelling and substitution of appropriate thermal and mechanical parameters, LIFE-PLAlE will be capable of analyzing fuel performance of $U_{3} S_{i}$ and U-Mo fuels under normal reactor operating conditions. Furthermore, fuel behavior under reactor transient: conditions can also be predicted by LIFE-PLATE with some code modifications which have already been employed in LIFE- $4 \mathrm{~T}^{12}$, a combined steady-state and transient fuel performance code for IMFBR fuel. 
REFERENCES

1. J. E. Matos, RERTR Program Generic Studies, Trans. Am. Nuc1. Soc. $\underline{32}$ Supp1. 1, 31 (1979).

2. D. Stahl, The Status and Development Potential of Plate-Type Fuels for Research and Test Reactors, Argonne National Laboratory Report ANL-79-11 (March 1979).

3. J. P. Schwartz, Uranium Dioxide Caramel Fuel, presented at International Conference on Nuclear Non-Proliferation and Safeguards, AIF, New York, Oct. 22-25, 1978.

4. J. Bernot and B. Lerouge, Osiris: Operation and Utilization Status, presented at CEA-CONF-1462, CEA, Saclay, France (Dec. 1969).

5. J. P. Schwartz, Combustible Caramel Pour Reacteurs De Recherche, presented at International Confërence on Nuclear Non-Proliferation and Safeguards, New York (October 1978).

6. M. L. Bleiberg, R. M. Berman, and B. Lustman, Effects of High Burn-Up on Oxide Ceramic Fuels, in Radiation Damage in Reactor Materials, IAEA, Vienna, 1963, pp. 319-428.

7. Light-Water-Reactor Safety Research Program - Quarterly Progress Report, July-September, 1976, Argonne National Laboratory Report, ANL-76-121, p. 48-61.

8. S. Timoshenko and J. N. Goddier, Thowry of Elasticity, 3rd Ed., McGrawHill, p. 448 (1970).

9. J. Rest and S. Geh1, The Mechanistic Prediction of Fission-Gas Behavior During In-CeIZ Transient Heating Tests on LWR Fuel Using the GRASS-SST and FASTGRASS Computer Codes, Trans. 5th Intl. Conf. on Structural Mechanics in Reactor Technology, Berlin, W. Gernany, Aug. 13-17, 1979, T. A. Jaeger and B. A. Boley, Eds. North-Holland Pub1. Co., 1979, Vol. C, paper C $1 / 6$.

10. J. Rest, SST: A computer Code to Predict Fuel Response and Fission Product Release From Light-Water Reactor Fuels During Steady-State and Transient Conditions, Trans. Am. Nucl. Soc. 22, 462 (1975).

11. R. C. Daniel, M. L. Bleiberg, H. B. Meieran, and W. Yeniscavich, Effects of High Bumup on Zircaloy-Clad, Bulk UO, Plate Fuel Element Samples, Bettis Atomic Power Laboratory Report WARD-263 (Sept. 1962).

12. Y. Y. Liu, LIFE4/4T Coupling, presented at LIFE Working Group Meeting, Richland, WA, September 28, 1979. 